\title{
Separation of Fuzzy Topological Space
}

\author{
Mohammad Arshaduzzaman, PhD \\ M.Sc (Mathematics) \\ Associate Professor \\ Department of Mathematics \\ Al Baha University, Al Baha \\ Kingdom of Saudi Arabia (KSA)
}

\begin{abstract}
In this paper I discussed about some separation properties of fuzzy topological space. The definition of fuzzy compactness does not hold good on the definition of fuzzy Hausdorff space, we introduce a new definition of proper compactness and prove some interesting results related with it.
\end{abstract}

\section{Keywords}

Fuzzy set, Fuzzy topological space, Fuzzy Hausdorff space, compactness, T2- space.

\section{INTRODUCTION}

Let $\mathrm{X}$ be any set. A fuzzy set $\mathrm{A}$ in $\mathrm{X}$ is characterized by membership function $\mu_{A}: X \rightarrow[0,1]$ A fuzzy singleton $p$ in $X$ is a fuzzy set with the membership function $\mu_{\mathrm{p}}$ defined by $\mu_{p}(X)=y$ if $x=x_{0}=0$ otherwise

where $y \in(0,1) \cdot x_{0}$ fuzzy set in $x$, if $\mu_{\mathrm{p}}\left(\mathrm{x}_{0}\right)<\mu_{\mathrm{A}}\left(\mathrm{x}_{0}\right)$

Hence $\mathrm{p} \notin$ Aiff $\mu_{\mathrm{p}}\left(\mathrm{x}_{0}\right) \geq \mu_{\mathrm{A}}\left(\mathrm{x}_{0}\right)$

\section{Definition 1 :}

A fuzzy topological space is said to be Housdorff of fuzzy T2 if the following conditions are satisfied :

For any $\mathrm{p}, \mathrm{q} \notin \mathrm{X}$,

(i) If $\mathbf{X}_{\mathrm{p}} \neq \mathrm{X}_{\mathrm{q}}$ then there exist open sets and Gp and $\mathrm{Gq}$ $p \in \bar{G}_{p}$ and $q \in G_{q}, p \in \bar{G}_{p}$

(ii) $\quad \mathrm{xp}=\mathrm{xq}$ and $\mu_{\mathrm{p}}\left(\mathrm{x}_{\mathrm{p}}\right)<\mu_{\mathrm{q}}\left(\mathrm{x}_{\mathrm{q}}\right) \Rightarrow$ there exist an open Gp with $p \in G_{p}$ but $q \notin \bar{G}_{p}$.

By Srivastava \& Lal [8].

\section{Definition 2 :}

A fuzzy set A is said to be open for each, there exists an open set $G$ with $P \in G \subseteq A$. Out definition of open set is equivalent to that given by Change [1].

\section{Definition 3 :}

A fuzzy topological space is said to be a fuzzy $\mathrm{T}_{1}$ - space if the singletons are closed. By Hutton \& Reilly [2].

\section{THEOREM (I)}

Every fuzzy $\mathrm{T}_{2}$ - space is a fuzzy $\mathrm{T}_{1}$ - space.

Proof : Let $(X, T)$ be a fuzzy $\mathrm{T}_{2}$ - space.

Case (i) : Let $p$ be a fuzzy point in $X$, and let $q \in\{p\}^{\prime}$ be arbitrary. Then, there exist an open set $\mathrm{G}_{\mathrm{q}}$ containing $\mathrm{q}$ such that

$\mu_{(p)}\left(x_{p}\right) \geq \mu G_{q}\left(x_{p}\right)$

Hence $G_{q}\{p\}$. So, $\{p\}$ being the union of open sets, is an open set. This implies that $\{p\}$ is closed.

Case (ii) : Let $\mathrm{p}$ be a crisp point and converges to zero, then we can find a sequence of open sets $\left\{G_{p q_{n}}\right\}_{n \in N}$ with $p \in G_{p q_{n}}$

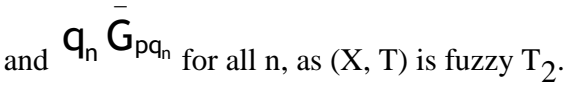

If $P=\cap \bar{G}_{p q_{n}}$ then $p$ is a closed set with $\mu_{\mathrm{p}}\left(\mathrm{x}_{\mathrm{q}}\right)=0$ and $\mu_{\mathrm{p}}\left(\mathrm{x}_{\mathrm{p}}\right)=1$

$\mathrm{p} \in \mathrm{V}_{\mathrm{pq}}$

So, $P^{\prime}$ is an open set with $q \in P^{\prime}\{p\}^{\prime}$ Consequently, $\{p\}^{\prime}$ is an open set i.e. $\{P\}$ is closed. So, $(X, T)$ is fuzzy $T_{1}$-space.

We now introduce the concept of properly compact space in a fuzzy

topological space and prove an analogous result of general topology which holds for a compact Hausdroff space.By Palaniappan[3] \& Zadeh[4]

\section{Definition 4 :}

A family $\left\{G_{1}: i \in l\right\}$ open sets in fuzzy topological space $X$ is called a proper open cover of a fuzzy set $\mathrm{A}$ in $\mathrm{X}$ if for every $X \in X$ there exists a member $G_{i_{x}}$ of this family such that of this family such that $\mu G_{i_{x}}(x) \geq \mu_{A}(x)$

The family $\left\{G_{i}: i \in l\right\}$ is called a proper open sub cover of $\left\{G_{i}: i \in l\right\}$ if it is itself a proper open cover of A.

By Lowen[5]. 


\section{Definition 5 :}

A fuzzy set A in a fuzzy topological space $X$ is said to be properly compact if every proper open cover of $\mathrm{A}$ is reducible to a finite proper open sub cover.

By Lowen [6] \& Rodabaugh[7].

\section{THEOREM 2}

Every properly compact set in a fuzzy $\mathrm{T}_{2}$ - space is closed.

Proof : Let A be a properly compact set in a fuzzy $\mathrm{T}_{2}$-space $\mathrm{X}$. We choose a point with

$$
\mu_{\mathrm{p}}\left(\mathrm{x}_{\mathrm{p}}\right)>\mu_{\mathrm{A}}\left(\mathrm{x}_{\mathrm{p}}\right)
$$

since $X$ is $T_{2}$, there exists an open $G_{p}$ with $\mu_{A}\left(x_{p}\right)<\mu_{G_{p}}\left(x_{p}\right)$

and $\mu_{\mathrm{p}}\left(\mathrm{x}_{\mathrm{p}}\right) \geq \mu_{\mathrm{G}_{\mathrm{p}}}-\left(\mathrm{x}_{\mathrm{p}}\right)$

Thus, for each such $\in X$ there exists a family $\left\{\mathrm{G}_{\mathrm{pq}}: \mathrm{x}_{\mathrm{q}} \in \mathrm{X}\right\}$ of open sets

with $\mu_{\mathrm{A}}\left(\mathrm{x}_{\mathrm{q}}\right)<\mu_{\mathrm{G}_{\mathrm{pq}}}\left(\mathrm{x}_{\mathrm{q}}\right)$ for all $\mathrm{x}_{\mathrm{q}} \in \mathrm{X}$ there exists a family $\left\{G_{p q}: X \in X\right\}$ of open sets $\mu_{A}\left(X_{q}\right)<\mu_{G_{p q}}\left(X_{q}\right)^{\text {with }}$ with (iv)

$$
\begin{aligned}
& \text { sup } \\
& \text { So, } \mu_{\mathrm{A}}\left(\mathrm{x}_{\mathrm{q}}\right) \leq \mathrm{x}_{\mathrm{q}} \in \mu_{\mathrm{G}_{\mathrm{pq}}}\left(\mathrm{x}_{\mathrm{p}}\right) \\
& \mathrm{A} \subseteq \underset{\mathrm{x}_{\mathrm{q}}}{\subseteq \mathrm{X}} \mathrm{G}_{\mathrm{pq}}
\end{aligned}
$$

Thus, the family $\left\{G_{p q}: x_{q} \in X\right\}$ is a proper cover of A. Since A is properly compact, there exists a finite subfamily, say,

$$
\left\{G_{p q 1}, G_{p q 2}, \ldots ., G_{p q m}\right\} \text { of }\left\{G_{p q}: x q \in X\right\} \text { of }\left\{G_{p q}: x_{q} X\right\}_{\text {with }}
$$

$A \subset \cup G_{p q k}$. Then $A \subset \cup_{\mathrm{K}=1}^{\mathrm{m}} \overline{\mathrm{G}}_{\mathrm{pqk}}=\mathrm{F}_{\mathrm{p}}$ (suppose)
Then $\mathrm{F}_{\mathrm{p}}$ is closed and $\mu_{\mathrm{p}}\left(\mathrm{x}_{\mathrm{p}}\right) \leq \mu_{\mathrm{Fp}}\left(\mathrm{x}_{\mathrm{p}}\right)$ for all $\mathrm{x}_{\mathrm{q}} \in \mathrm{X}_{\text {(v) }}$

We also have $\mu_{\mathrm{p}}\left(\mathrm{x}_{\mathrm{p}}\right) \geq \mu_{\mathrm{Fp}}\left(\mathrm{x}_{\mathrm{p}}\right)$

Then, for all satisfying the condition (i), the family $\left\{F_{p}\right\}$ where $F_{p}^{\prime}$ is open in $X$, satisfies the conditions (v) \& (vi). Consequently we have $\mu_{\mathrm{A}}\left(\mathrm{x}_{\mathrm{q}}\right)=\operatorname{lnf}_{\mathrm{p}} \mu_{\mathrm{Fp}}\left(\mathrm{x}_{\mathrm{q}}\right)$ for all $\mathrm{x}_{\mathrm{q}} \in \mathrm{X}$.

Then, $\quad \bigcap_{p} F_{p}$ with establishes that $A$ is closed.

\section{CONCLUSION}

From the above theorems and definitions it is clear that A fuzzy set in a fuzzy topological space is said to be properly compact if every proper open cover of a fuzzy set is reducible to a finite proper open sub cover and every properly compact set in a fuzzy $\mathrm{T}_{2}$-space is closed. Thus the definition of fuzzy compactness does not hold good on the definition of fuzzy Hausdorff space.

\section{REFERENCES}

[1] Chang, C.L. : Fuzzy topological spaces, J.Math. Anal. Appl. 24, 182-190, 1960.

[2] Hutton, B \& Reilly, I. : Seperation axioms in fuzzy topological space, Fuzzy Sets \& systems 3, 99-104, 1980.

[3] Palaniappan, N. : Fuzzy topology, Narosa Publ. House, New Delhi, 2002.

[4] Zadeh, L.A. : Fuzzy sets, Inform, Control, 8, 338-353.

[5] Lowen R : Fuzzy topological spaces and fuzzy compactness,J. Math. Anal. Appl.,56 (1976), pp.621-633.

[6] Lowen R: Compact Hausdorff fuzzy topological spaces are topological, Topology and Appl., 12 (1981), pp. 6574.

[7] Rodabaugh $S$ :The Hausdorff separation axiom for fuzzy topological spaces,Topol. Appl.,11 (1980),pp. 319-334.

[8] Srivastava R, Lal S N, and Srivastava A K, "Fuzzy Hausdorff topological spaces," Journal of Mathematical Analysis and Applications, vol. 81, no. 2, pp. 497-506, 1981. 